\title{
Association of Demographic and Occupational Factors with SARS-CoV-2 Vaccine Uptake in Kenya
}

\section{Bertha A. Ocholla ${ }^{1}$, Obed Nyangena ${ }^{2}$, Herbert K. Murayi ${ }^{1}$, Jane W. Mwangi ${ }^{1}$, Steve K. Belle ${ }^{1}$, Phanice Ondeko1, Rebecca Kendagor ${ }^{1}$}

${ }^{1}$ Kenyatta National Hospital, Nairobi, Kenya

${ }^{2}$ Kenya School of Government, Nairobi, Kenya

Email: berthaanyango83@gmail.com

How to cite this paper: Ocholla, B.A., Nyangena, O., Murayi, H.K., Mwangi, J.W., Belle, S.K., Ondeko, P. and Kendagor, R. (2021) Association of Demographic and Occupational Factors with SARS-CoV-2 Vaccine Uptake in Kenya. Open Access Library Journal, 8: e7424.

https://doi.org/10.4236/oalib.1107424

Received: April 15, 2021

Accepted: May 16, 2021

Published: May 19, 2021

Copyright $\odot 2021$ by author(s) and Open Access Library Inc.

This work is licensed under the Creative Commons Attribution International License (CC BY 4.0).

http://creativecommons.org/licenses/by/4.0/

\begin{abstract}
The outbreak of the Severe Acute Respiratory Syndrome Coronavirus 2 has triggered adoption and diffusion of public and infection control measures. After numerous clinical trials, various brands of vaccines were developed to attenuate further spread of the virus. The vaccines come at a time when misinformation is scuttling synergies to fight the flu-like disease. Uncertainty surrounding the safety of the vaccines translates to fear of health outcomes among users yet hesitancy in vaccine uptake has direct threats to health. Using a digital cross-sectional survey data among 171 respondents that was conducted between $2^{\text {nd }}$ March and $5^{\text {th }}$ March 2021, the study reveals variation on the update of the vaccine. The study recommends public sensitization and education about the vaccines for greater proportion of acceptance and uptake.
\end{abstract}

\section{Subject Areas}

Health

\section{Keywords}

Mitigation Measures, Variants, Blood Clots, Fear, Awareness, AstraZeneca

\section{Background}

The 2019 Severe Acute Respiratory Syndrome Coronavirus 2 (SARS-CoV-2) broke out in a wet market in Wuhan, Hubei province, China at the end of 2019 (Xiang et al., 2020) [1]. The disease was later declared as a Public Health Emergency of International Concern (PHEIC) by the World Health Organization 
(WHO) in January 2020 and as a global pandemic in March 2020.

Kenya confirmed the first case of SARS-CoV-2 on 12 March 2020. A year on, more than 109,643 cases (an equivalent of $2.7 \%$ of all African cases) and 1,886 deaths had been reported. As the number of cases continued to soar, experts warned about emergence of variants that could be difficult to manage (WHO, 2021) [2]. The mutating nature of SARS-CoV-2 necessitates stricter adherence to mitigation measures that include isolations and quarantines, handwashing with soap or alcohol-based sanitizers and use of face coverings.

Although clinical research has provided apposite information about the structure and behavior of the mutating air-borne virus and the widened prospects for the development of an effective vaccine, there is uncertainty on the safety and effectiveness of the vaccines, issues that are largely attributable to ethics, history and conspiracy. Kenya was among other first African countries that received the first batch of AstraZeneca vaccines amid speculation, mainly in Europe, that the vaccine causes blood clots (see Dyer, 2021 [3]; Wise, 2021 [4]). Outside Africa, studies reveal a sizable proportion in hesitancy for inoculation. This is despite assurances that inoculation benefits far outweigh the risks. Padhi and Al-Mohaithef (2020) [5] have observed that successful inoculation is context-specific and varies with geography and socio-demographics, an issue the article sought to ascertain.

\section{Literature Review}

The Health Belief Model (HBM) is used in explaining vaccination behaviour (see Brewer \& Fazekas, 2007 [6]; Gerend \& Shepherd, 2012 [7]; Vermandere et al., 2016 [8]). The HBM accounts for the perceived severity, vulnerability and awareness of the benefits; cultural or socio-demographic barriers and characteristics; willingness to get vaccinated and diffusion in the uptake of the vaccine.

Increasingly, evidence-based medicine (EBM) has been embraced as a new way to standardize clinical care. However, EBM might generate new uncertainties that are attributable to widened leveraging on information technologies and epidemiological models. Since humanity is subject to fear and uncertainty when faced with danger, it can be concluded that EBM does not eliminate the humanitarian values in clinical care. As countries continue to report new variants (e.g. Bugembe et al., 2021 [9]; Yadav et al., 2021 [10]), more than a dozen vaccines have been developed and approved. The efficacy of many more is being tested. Kazi and Mursheda (2020) [11] have argued that it is through these efforts that the world will attenuate and fully eradicate the disease.

Development of the much needed vaccine(s) does not translate to people's acceptance as Seale et al., (2021) [12] have observed who have drawn insights from previous pandemics particularly the 2009 influenza virus pandemic. A meta-analysis on SARS-CoV-2 vaccine acceptance among 33 different studies suggests a worrying level of acceptance in Africa (Sallam, 2021) [13]. As Askarian et al., (2020) [14] have revealed, vaccine refusal is mainly driven by misconceptions 
about vaccine efficacy and its attendant adverse effects. Insights from the influenza pandemic reveal that gender, marital status, one's perception of the risk and valuing experts' recommendation are imperative in increasing the likelihood of inoculation among at risk populations (Malik et al., 2020 [15]; Padhi \& Al-Mohaithef, 2020 [5]).

Herd immunity is unattainable, if only few people can access the vaccine, no matter the clinical effectiveness of a particular vaccine. Vaccine hesitancy that is characterized by uncertainty and ambivalence about vaccination can be resolved by convincing the general public of the safety, efficacy and necessity of the vaccine (Razai et al., 2021) [16].

\section{Methodology}

The study employed a cross-sectional survey, using a quantitative technique to establish the determinants of SARS-CoV-2 vaccine acceptance and uptake in Kenya. An online, self-designed questionnaire of opinion and attitude, which was hosted on Google was used. The questionnaire contained short, simple yet relevant questions on the respondents' perceptions on the uptake of the SARS-CoV-2 vaccine. Consistency and neutrality in questioning was ensured and no bias or emotional elements were asked. The survey link was shared via email. For ethical purposes, the respondents were auto-directed to the informed consent page and allowed to fill out the form, which remained open for four days between $2^{\text {nd }}$ March and $5^{\text {th }}$ March, 2021.

The Cochran formula was used in computation of the sample size. The formula is given as: $n_{0}=\frac{Z^{2} \varphi \omega}{e^{2}}$, where: $n$ is the sample size; $\varphi$ is the estimated population with varying socio-demographics; $\omega$ is $1-\varphi$, and $e$ is the desired level of accuracy. However, computation of the adjusted sample size, $n$, where smaller populations are involved, the formula is assembled by using the equation: $n=\frac{n_{0}}{1+\frac{\left[n_{0}-1\right]}{N}}$, where: $n_{0}$ represents the Cochran's sample; $N$ represents the population size. The target population consisted of 470 individuals across the 47 counties in Kenya. By applying the Cochran's formula (assuming 90\% response rate) it follows that:

$$
n=\frac{423}{1+\frac{[423-1]}{470}}=222
$$

\section{Methodological Assumption}

For purposes of this study, it is assumed that the Google Form developed, was only shared within Kenya and filled out by respondents of consenting age and of desired attributes. Anonymized data was used for analysis and interpretation. No individual information or data that may lead to identity disclosure was gathered or included in this study. 


\section{Results and Discussion}

A total of 171 respondents participated in the study. This was an equivalent of $77 \%$ of the desired sample size. Out of this number, $60 \%$ were male and approximately two-thirds (66\%) were aged between 36 - 60 years old. As shown in Table 1, the number of respondents who had a degree and post-graduate degree was proportionate, at 68 and 67 , respectively.

Although $98.2 \%$ of the respondents were aware of the availability of SARS-CoV-2 vaccine around the world, nearly half (47.3\%) reported watching television as their source of information about the pandemic. Other statistics are revealed in Table 2 .

Among the participants $(n=170)$ who responded to the question on willingness to receive the COVID-19 vaccine, only slightly above average (52.4\%) were willing to be inoculated. Out of those who were unwilling to be inoculated, the majority alleged concerns on the side effects. A Chi ${ }^{-}$square test revealed only profession of the respondents was significant, $\left.\mathrm{X}^{2}(1, \mathrm{~N}=170)=5.321, \mathrm{p}=0.021\right)$ as revealed on Table 3 .

Studies reveal that vaccines are needed to attenuate spread of SARS-CoV-2

Table 1. Participants' demographic information.

\begin{tabular}{|c|c|c|}
\hline Characteristic & Attribute & n (\%) \\
\hline \multirow{2}{*}{ Gender } & Male & $103(60.2 \%)$ \\
\hline & Female & $68(39.2 \%)$ \\
\hline \multirow{3}{*}{ Age (years) } & $<36$ & $58(33.9 \%)$ \\
\hline & $36-60$ & $112(65.5 \%)$ \\
\hline & $>60$ & $1(0.6 \%)$ \\
\hline \multirow{3}{*}{ Marital status } & Married & $119(69.6 \%)$ \\
\hline & Single & $50(29.2 \%)$ \\
\hline & Widowed & $2(1.2 \%)$ \\
\hline \multirow{4}{*}{ Religion } & Christian & $165(96.5 \%)$ \\
\hline & Muslim & $2(1.2 \%)$ \\
\hline & Hindu & $1(0.6 \%)$ \\
\hline & Other & $3(1.8 \%)$ \\
\hline \multirow{8}{*}{ Level education } & Secondary & $1(0.6 \%)$ \\
\hline & Certificate & $4(2.4 \%)$ \\
\hline & Diploma & $16(11.8 \%)$ \\
\hline & Higher Diploma & $6(3.5 \%)$ \\
\hline & Degree & $68(39.8 \%)$ \\
\hline & Post graduate degree & $67(39.2 \%)$ \\
\hline & $\mathrm{PhD}$ & $7(4.1 \%)$ \\
\hline & Other & $1(0.6 \%)$ \\
\hline \multirow{2}{*}{ Profession } & Medic & $69(40.4 \%)$ \\
\hline & Non-medic & $102(59.6 \%)$ \\
\hline
\end{tabular}


Table 2. Source of information of SARS-CoV-2 vaccine.

\begin{tabular}{llc}
\hline \multicolumn{1}{c}{ Characteristic } & & n (\%) \\
\hline \multirow{2}{*}{ Aware of SARS-CoV-2 vaccine } & Yes & $168(98.2)$ \\
\hline & No & $3(1.8)$ \\
\hline Source of information (on vaccine availability) & Radio & $10(5.9)$ \\
& Social Media & $80(47.3)$ \\
& Friends & $49(29.0)$ \\
& Workplace & $4(2.4)$ \\
Aware that government procured SARS-CoV-2 vaccine & Healthcare workers & $14(8.3)$ \\
& Other & $11(6.5)$ \\
& No & $168(9.6)$ \\
\hline & Radio & $3(1.8)$ \\
\hline Source of information on government having procured & TV & $10(5.8)$ \\
& Friends & $102(59.6)$ \\
& Workplace & $37(21.6)$ \\
& Healthcare workers & $10(5.8)$ \\
& Other & $1(0.6)$ \\
\hline
\end{tabular}

Table 3. Chi-square test results.

\begin{tabular}{|c|c|c|c|c|c|}
\hline \multirow[t]{2}{*}{ Characteristic } & & \multicolumn{2}{|c|}{$\begin{array}{l}\text { Willingness to accept } \\
\text { the vaccine (\%) }\end{array}$} & \multirow{2}{*}{$\mathrm{p}$} & \multirow[t]{2}{*}{$\mathrm{X}^{2}$} \\
\hline & & Yes & No & & \\
\hline \multirow{2}{*}{ Gender } & Male & 58.3 & 41.7 & 0.80 & 3.071 \\
\hline & Female & 43.3 & 56.7 & & \\
\hline \multirow{3}{*}{ Age } & $<36$ years & 44.8 & 55.2 & & \\
\hline & 36 - 60 years & 56.8 & 43.2 & & \\
\hline & $<60$ years & 0 & 100 & & \\
\hline \multirow{2}{*}{ Profession } & Medic & 63.8 & 36.2 & 0.021 & 5.321 \\
\hline & Non-medic & 44.6 & 55.4 & & \\
\hline \multirow{2}{*}{$\begin{array}{l}\text { Aware of the availability } \\
\text { of SARS-CoV-2 vaccine }\end{array}$} & Yes & 53.3 & 46.7 & 0.212 & 1.559 \\
\hline & No & 0 & 100 & & \\
\hline \multirow{3}{*}{$\begin{array}{l}\text { Aware of government } \\
\text { having procured vaccine }\end{array}$} & Yes & 52.7 & 47.3 & 0.93 & 0.007 \\
\hline & No & 33.3 & 66.7 & 0.366 & 2.010 \\
\hline & Married & 55.9 & 44.1 & & \\
\hline \multirow[t]{2}{*}{ Marital Status } & Single & 44.0 & 56.0 & & \\
\hline & Widowed & 50.0 & 50.0 & & \\
\hline
\end{tabular}


(Malik et al., 2020). The study findings reveal more women than men unwilling to be inoculated. This necessitates development of strategies that are aimed at addressing vaccine scepticism and ensure its success along occupation and gender lines.

\section{Conclusions and Recommendations}

\subsection{Conclusions}

New variants of SARS-CoV-2 could proliferate the number of confirmed cases in Kenya. While information sharing about the spread of the disease can strengthen update of mitigation measures, there is uncertainty on the safety of the vaccine(s). Majority of Kenyans get critical information about SARS-CoV-2 mainly on television or social media. If medical specialists, who have a higher acceptance index could take their jabs on television, it can go a long way in deepening acceptance among the general public. The medical specialists should hold television and socio-media campaigns to dispel the wrong narrative about the potential side effects of being inoculated for the benefits far outweigh any potential side effects, on a global scale.

\subsection{Recommendations}

The study finding revealed that unfounded fear about the potential side effects of the vaccines alongside safety and misinformation were leading drivers attributable to the low scale of acceptance of the vaccine(s) among the general public. To turn around this perception, the Ministry of Health should encourage public sensitization and education about the vaccine through available channels, mainly TV and social media. Lastly, given that men are more likely to be inoculated that women, a gendered approach to reverse vaccine scepticism is needed.

\subsection{Limitation of the Study}

The online survey, which was used in the study is not without its own limitations. It tends to exclude uneducated majority of the general public.

The perceived uncertainties around the SARS-CoV-2 vaccine uptake were restricted to the AstraZeneca vaccine. Plausibly, had respondents been presented with an array of vaccine brands that would have provided choice among users leading to overly different results. Perhaps, continued monitoring of trends on uptake could have provided meaningful insights on behavioural change over time. Beyond the assurance given by the government (and the manufacturer) on the safety of the vaccines, no experiment was carried out to bolster or weaken the assurances.

\section{Conflicts of Interest}

The authors declare no conflicts of interest regarding the publication of this paper. 


\section{References}

[1] Xiang, Y.-T., Yang, Y., Li, W., Zhang, L., Zhang, Q., Cheung, T. and Ng, C.H. (2020) Timely Mental Health Care for the 2019 Novel Coronavirus Outbreak Is Urgently Needed. The Lancet Psychiatry, 7, 228-229. https://doi.org/10.1016/S2215-0366(20)30046-8

[2] World Health Organisation (2021) The Effects of Virus Variants on COVID-19 Vaccines.

https://www.who.int/news-room/feature-stories/detail/the-effects-of-virus-variantson-covid-19-vaccines

[3] Dyer, O. (2021) Covid-19: EMA Defends AstraZeneca Vaccine as Germany and Canada Halt Rollouts. BMJ, 373, Article No. n883. https://doi.org/10.1136/bmj.n883

[4] Wise, J. (2021) Covid-19: European Countries Suspend Use of Oxford-AstraZeneca Vaccine after Reports of Blood Clots. BMJ, 372, Article No. n699.

https://doi.org/10.1136/bmj.n699

[5] Padhi, B.K. and Al-Mohaithef, M. (2020) Determinants of COVID-19 Vaccine Acceptance in Saudi Arabia: A Web-Based National Survey. medRxiv. [Preprint] https://doi.org/10.1101/2020.05.27.20114413

[6] Brewer, N.T. and Fazekas, K.I. (2007) Predictors of HPV Vaccine Acceptability: A Theory-Informed, Systematic Review. Preventive Medicine, 45, 107-114.

https://doi.org/10.1016/j.ypmed.2007.05.013

[7] Gerend, M.A. and Shepherd, J.E. (2012) Predicting Human Papillomavirus Vaccine Uptake in Young Adult Women: Comparing the Health Belief Model and Theory of Planned Behavior. Annals of Behavioral Medicine, 44, 171-180. https://doi.org/10.1007/s12160-012-9366-5

[8] Vermandere, H., Van Stam, M.A., Naanyu, V., Michielsen, K., Degomme, O. and Oort, F. (2016) Uptake of the Human Papillomavirus Vaccine in Kenya: Testing the Health Belief Model through Pathway Modeling on Cohort Data. Globalization and Health, 12, Article No. 72. https://doi.org/10.1186/s12992-016-0211-7

[9] Bugembe, D.L., Phan, M.V., Ssewanyana, I., Semanda, P., Nansumba, H., Dhaala, B., et al. (2021) A SARS-CoV-2 Lineage A Variant (A. 23.1) with Altered Spike Has Emerged and Is Dominating the Current Uganda Epidemic. MedRxiv. [Preprint] https://doi.org/10.1101/2021.02.08.21251393

[10] Yadav, P. D., Nyayanit, D. A., Sahay, R. R., Shete, A. M., Majumdar, T., Patil, S., et al. (2021) Imported SARS-CoV-2 V501Y. V2 Variant (B. 1.351) Detected in Travelers from South Africa and Tanzania to India. Travel Medicine and Infectious Disease, 41, Article ID: 102023. https://doi.org/10.1016/j.tmaid.2021.102023

[11] Kazi Abdul, M. and Khandaker Mursheda, F. (2020) Knowledge, Attitude and Acceptance of a COVID-19 Vaccine: A Global Cross-Sectional Study. International Research Journal of Business and Social Science, 6, 1-23.

[12] Seale, H., Heywood, A.E., Leask, J., Sheel, M., Thomas, S., Durrheim, D.N., et al. (2020) COVID-19 Is Rapidly Changing: Examining Public Perceptions and Behaviors in Response to This Evolving Pandemic. PLoS ONE, 15, e0235112.

https://doi.org/10.1371/journal.pone.0235112

[13] Sallam, M., Dababseh, D., Yaseen, A., Al-Haidar, A., Ababneh, N.A., Bakri, F.G. and Mahafzah, A. (2020) Conspiracy Beliefs Are Associated with Lower Knowledge and Higher Anxiety Levels Regarding COVID-19 among Students at the University of Jordan. International Journal of Environmental Research and Public Health, 17, Article No. 4915. https://doi.org/10.3390/ijerph17144915 
[14] Askarian, M., Fu, L., Taghrir, M.H., Borazjani, R., Shayan, Z., Taherifard, E., et al. (2020) Factors Affecting Covid-19 Vaccination Intent among Iranians: COVID-19 Vaccination Acceptance. http://doi.org/10.13140/RG.2.2.36788.48002

[15] Malik, A.A., McFadden, S.M., Elharake, J. and Omer, S.B., (2020) Determinants of COVID-19 Vaccine Acceptance in the US. EClinicalMedicine, 26, Article ID: 100495. https://doi.org/10.1016/j.eclinm.2020.100495

[16] Razai, M.S., Osama, T., McKechnie, D.G. and Majeed, A. (2021) Covid-19 Vaccine Hesitancy among Ethnic Minority Groups. BMJ, 372, Article No. n513. https://doi.org/10.1136/bmj.n513 